Ciência Florestal, Santa Maria, v. 24, n. 3, p. 565-572, jul.-set., 2014

ISSN 0103-9954

\title{
MATURAÇÃO E COLHEITA DA SEMENTE DE Amburana cearensis (Allem.) A. C. Smith
}

\author{
MATURATION AND HARVEST OF SEED DE Amburana cearensis (Allem.) A.C. Smith.
}

\author{
Izabela Souza Lopes $^{1}$ Assíria Maria Ferreira da Nóbrega² Valderez Pontes Matos $^{3}$
}

\begin{abstract}
RESUMO
Estudos sobre a maturação de sementes são fundamentais para orientar a época ideal de colheita, auxiliar o planejamento do processo de secagem, armazenamento e no controle da qualidade. Por isso, o trabalho teve como objetivo conhecer a época adequada para colheita de sementes de Amburana cearensis (Allem.) A. C. Smith. Os frutos foram coletados no município de Malta - Paraíba, e depois conduzidos ao Laboratório de Sementes da Universidade Federal de Campina Grande, onde procederam as análises e testes de germinação. Em cada uma das seis colheitas, realizadas semanalmente, foram avaliados frutos e sementes, quanto à coloração, biometria e teor de água, além da massa seca, germinação e vigor das sementes. O delineamento experimental foi o inteiramente casualizado com quatro repetições de 25 sementes cada. Os resultados obtidos permitiram constatar que 54 dias após a antese, estádio esse anterior à deiscência dos frutos, estes se apresentavam de coloração marrom-escura, enrugados e com fendas no ápice, enquanto as sementes no ponto ideal de maturação fisiológica, de coloração preta, germinação de $94,0 \% ; 3,0 \%$ de plântulas anormais e 1,0\% de sementes mortas para condições de semiárido nordestino. Recomenda-se a colheita dos frutos aos 54 dias após a antese quando apresentam coloração marrom-escura e ápice enrugado com fendas, pois aos 63 dias após a antese há a dispersão natural das sementes.
\end{abstract}

Palavras-chave: cumaru; maturidade fisiológica; frutificação; germinação.

\begin{abstract}
Studies about the maturation of seeds are essential to guide the ideal time of harvest, to assist the drying process planning, for storage and quality control. Therefore, the work aimed to know the appropriate time to harvest seeds from Amburana cearensis (Allem.) A. C. Smith. The fruits were collected in the city of Malta, in Paraíba state, and then taken to the seed laboratory at the Universidade Federal de Campina Grande, where the analyses and the germination tests were carried out. In each of the six harvests, held weekly, fruits and seeds were evaluated for staining, biometrics and water content addition of the dry mass, germination and vigor of seeds. The experimental design was completely randomized with four replications of 25 seeds each. The revealed results have found that 54 days after anthesis, this stadium prior to dehiscence of fruits, these were dark brown color, wrinkled and with cracks at the apex, while the seeds in the sweet spot of physiological ripeness, black coloring, germination of $94,0 \% ; 3,0 \%$ of abnormal seedlings and dead seed for $1.0 \%$ in the northeastern semi-arid conditions, it is recommended to harvest of the fruits to 54 days after anthesis when they presented a dark brown color and wrinkled apex with cracks, once 63 days after anthesis there is the natural dispersion of seeds.
\end{abstract}

Keywords: cumaru; physiological maturity; fruiting; germination.

1 Engenheira Florestal, Dra ${ }^{\mathrm{a}}$, Centro de Ciência e Agrárias, Universidade Federal da Paraíba, Campus II, CEP 58397000, Areia (PB), Brasil. izabelaisl@yahoo.com.br

2 Engenheira Florestal, Dra ${ }^{\text {., }}$ Professora do Departamento de Engenharia Florestal, Universidade Federal de Campina Grande, Caixa Postal 64, CEP 58708-110, Patos (PB), Brasil. anfnobrega@ig.com.br

3 Engenheira Agrônoma, Dr ${ }^{\mathrm{a}}$., Professora Associada do Departamento de Agronomia, Universidade Federal Rural de Pernambuco, Av. D. Manoel de Medeiros, s/n, Dois Irmãos, CEP 52171-900, Recife (PE), Brasil. vpmatos@ig.com.br

Recebido para publicação em 11/11/2011 e aceito em 8/04/2013

Ci. Fl., v. 24, n. 3, jul.-set., 2014 


\section{INTRODUÇÃO}

A caatinga caracteriza-se pela predominância de vegetação xerófila essencialmente extrativista, com problemas graves para as espécies mais procuradas, o que compromete a biodiversidade e causa problemas ambientais. Estudos básicos sobre as espécies que compõem este complexo vegetacional são essenciais para ampliar o conhecimento de tais espécies para manutenção da composição do bioma.

A Amburana cearensis (Allemao) A.C. Smith (Torresia cearensis Allemao), pertencente à família das Fabaceae, é uma árvore de caule ereto, que chega a atingir de10 a $12 \mathrm{~m}$ de altura (SANTOS et al., 2009). Por suas qualidades madeireiras tem sido explorada até a sua exaustão nos locais de ocorrência e tem usos em movelaria fina, esculturas e marcenaria em geral. Esta espécie encontra-se na lista de espécie em extinção (IBAMA, 1992).

Para as pesquisas científicas e empregabilidade de suas descobertas, como a recomposição ou implantação de florestas ou o manejo de populações de plantas, é necessário conhecer a época de colheita de sementes de espécies florestais nativas, bem como o processo germinativo, para que informações sobre as características auxiliem na busca de alternativas para o reflorestamento, arborização urbana e de rodovias, recomposição de áreas degradadas, a partir de espécies que se adaptem às condições adversas de altas variações climáticas e edáficas na caatinga.

Segundo Aguiar et al. (1993), o conhecimento sobre a maturação das sementes de espécies florestais é ferramenta para se entender a dinâmica das florestas, sua biologia, e ecologia das florestas, para, no futuro, possibilitar o manejo e conservação das populações naturais. Estudos de maturação de sementes ainda são de fundamental importância para orientar a época ideal de colheita, auxiliar o planejamento dessa operação no processamento, secagem, armazenamento e no controle da qualidade. Para Marcos Filho (2005), a maturação da semente é considerada resultado de todas as alterações morfológicas, físicas e fisiológicas, como o aumento do tamanho e as variações no grau de umidade, no vigor e no acúmulo de massa seca, iniciando com a fertilização e estendendo-se até a maturidade fisiológica, ponto esse, que apresenta as melhores condições para a semente germinar com maior vigor e proporcionar uma plântula morfologicamente normal. Por isso, este trabalho teve como objetivo identificar a época adequada para colheita de sementes de Amburana cearensis (Allem) A. C. Smith.

\section{MATERIAL E MÉTODOS}

O estudo foi realizado no ano de $2008 \mathrm{em}$ área de Caatinga no município de Malta - Paraíba - Brasil, a uma distância de $28 \mathrm{~km}$ da cidade de Patos - Paraíba - Brasil, situada a $07^{\circ} 01^{\prime}$ latitude Sul e $37^{\circ} 17^{\prime}$ longitude oeste, com altitude média de $250 \mathrm{~m}$. O clima é do tipo BSh (quente e seco), com precipitação média anual entre 250 e $800 \mathrm{~mm}$, concentrada principalmente nos meses de fevereiro a abril, temperatura média de $29^{\circ} \mathrm{C}$ com vegetação xerófila.

Foram selecionadas dez árvores matrizes, sendo vigorosas e com boa aparência fitossanitária, com distância mínima de 50 metros entre elas. As observações foram realizadas semanalmente, monitorando a fenologia reprodutiva, após se constatar que $50,0 \%$ das inflorescências das árvores selecionadas se encontravam em antese, procedeuse a marcação das inflorescências utilizando-se fitas vermelhas, a partir dessa época foi realizado o acompanhamento do desenvolvimento dos frutos e sementes até a dispersão das mesmas.

Foram colhidos 20 frutos de cada árvore, do $26^{\circ}$ até o $63^{\circ}$ dia após a antese, com características semelhantes de tamanho e coloração, os quais foram acondicionados em sacos de polietileno e encaminhados ao Laboratório de Análise de Sementes do Centro de Saúde e Tecnologia Rural da Universidade Federal de Campina Grande UFCG. Dentre o total de frutos colhidos, 100 frutos e 100 sementes foram selecionados aleatoriamente e, posteriormente, foram avaliados os seguintes parâmetros: coloração, biometria, massa seca eteor de água dos frutos e sementes. Além destes parâmetros determinaram-se o potencial germinativo e o índice de velocidade de germinação (IVG) das sementes (MAGUIRE, 1962). Para a realização dos testes, as sementes foram retiradas manualmente dos frutos, ou seja, com corte longitudinal seguindo-se de retorcimento dos frutos para facilitar a retirada das sementes, as utilizadas para o teste de germinação foram colocadas em bandeja plástica à sombra em laboratório com temperatura de $26^{\circ} \mathrm{C}$ durante 24 horas, antes de serem semeadas.

$\mathrm{O}$ teor de água foi determinado pelo método de estufa a $105^{\circ} \mathrm{C} \pm 3^{\circ} \mathrm{C}$ durante 24 horas (BRASIL, 2009). Após a colheita dos frutos, foram 
obtidas duas amostras de 10,0 g para os frutos, e duas amostras de 5,0 g para as sementes sem ala. Após a secagem, as amostras foram colocadas em dessecador, por 15 minutos, e em seguida feitas as pesagens em balança analítica com precisão de $0,001 \mathrm{~g}$. Os resultados obtidos foram expressos em mg.unidade ${ }^{-1}$.

A massa seca das sementes foi obtida conjuntamente com o teor de água, nas seis épocas de colheitas estabelecidas, após permanência em estufa a $105^{\circ} \mathrm{C} \pm 3^{\circ} \mathrm{C}$ por 24 horas (BRASIL, 2009). Os resultados obtidos foram expressos em g.unidade ${ }^{-1}$.

A cada colheita, foi determinado o comprimento, largura e espessura de 100 frutos e 100 sementes, com auxílio de um paquímetro digital com precisão de $0,01 \mathrm{~mm}$, o resultado obtido foi expresso em $\mathrm{mm}$.

Para as seis épocas de colheita foram utilizadas quatro repetições com 25 sementes desinfetadas com hipoclorito de sódio a 10,0\%, por 5 minutos, e lavadas com água destilada cinco vezes. As sementes foram semeadas entre substrato areia, previamente esterilizado em estufa a $150^{\circ} \mathrm{C}$ por 24 horas e acondicionadas em caixas plásticas $(11,0 \times 11,0 \times 3,5 \mathrm{~cm})$ transparentes, irrigadas com água destilada quando necessário e depositadas na bancada de laboratório a temperatura média de $26^{\circ} \mathrm{C}$, Patos $-\mathrm{PB}$.

O teste de germinação foi avaliado do terceiro ao trigésimo dia de semeadura, diariamente e no mesmo horário, utilizando como critério de germinação a emergência do hipocótilo. Após este período, as plântulas foram retiradas da areia, com auxílio de água corrente, e avaliadas como normais ou anormais. Foram consideradas plântulas normais, aquelas que apresentaram sistema radicular, hipocótilo, epicótilo, cotilédones e protófilos desenvolvidos, e plântulas anormais, aquelas com desenvolvimento anormal em algumas de suas partes. As sementes não germinadas foram computadas como duras ou mortas (BRASIL 2009).

O delineamento estatístico utilizado foi inteiramente casualizado, os dados foram submetidos à análise de variância por meio do programa ASSISTAT Versão 7.5 beta (2008), e as médias foram comparadas pelo teste de Tukey a $5,0 \%$ de probabilidade. Os dados de germinação e IVG foram considerados para análise de variância da regressão polinomial, linear e quadrática, em função das seis épocas de colheita, sendo selecionado para explicar os resultados, o modelo significativo de maior ordem. Para a porcentagem de germinação, os dados foram transformados em arc seno $(\mathrm{X} / 100)^{1 / 2}$.

\section{RESULTADOS E DISCUSSÃO}

As observações iniciaram no dia 25 de maio de 2008, quando se verificou a presença de botões florais da espécie em estudo. Em 30 de julho de 2008 constatou-se a abertura dos botões florais (antese), e no dia 14 de agosto de 2008 a presença de frutos pequenos de aproximadamente um $(01) \mathrm{cm}$, no dia 25 de agosto de 2008 foi realizada a primeira colheita, em virtude do fruto está totalmente formado. Foram observados seis estádios de maturação e a dispersão das sementes ocorreu aos 63 dias após a antese,

Registraram-se alterações na coloração dos frutos e sementes durante o processo de maturação (Tabela 1), os frutos variaram da cor verde com manchas amareladas a marrom-escuras, enrugados

TABELA 1: Época de colheita, coloração dos frutos e sementes de Amburana cearensis em diferentes estádios de maturação.

TABLE 1: Harvest season, colouring of fruits and seeds of Amburana cearensis in various stages of ripening.

\begin{tabular}{cccc}
\hline N. Colheita & $\begin{array}{c}\text { Dias após a } \\
\text { antese }\end{array}$ & Coloração do fruto & Coloração da semente \\
\hline $1^{\text {a }}$ & 26 & Verde com manchas amareladas & Rosa \\
$2^{\text {a }}$ & 33 & Marrom-claro & Rosa \\
$3^{\text {a }}$ & 40 & Marrom-escuro & Vinho \\
$4^{\text {a }}$ & 48 & Marrom-escuro & Vinho-escuro \\
$5^{\text {a }}$ & 54 & Com ápice marrom-escuro e enrugado & Pretas com ala translúcida \\
$6^{\text {a }}$ & 63 & Aberto com dispersão de sementes & Preta com ala creme \\
\hline
\end{tabular}


e opacos, enquanto as sementes variaram de rosa a preta com ala cor creme. Estas características podem ser consideradas um bom índice para indicar a época ideal de colheita das sementes, pois, visualmente, é possível identificar a maturidade das sementes em campo antes da colheita, não necessitando de análises em laboratório.

O índice de coloração de frutos e sementes também tem sido utilizado como bom indicador do ponto de colheita, como foi comprovado por Ávila et al. (2009) em trabalho realizado com Eugenia uniflora L.; Germaque et al. (2002) com Tabebuia impetiginosa (Mart.) Standl.; Lopes e Soares (2006) com Miconia cinnamomifolia (Dc.) Naud.; Martins et al. (2008a), com Jacarandá cuspidifolia Mart. Porém, para Martins et al. (2008b), com Tabebuia chrysotricha (Mart. ex DC.) Standl.), a coloração dos frutos não foi um bom indicadores da época de colheita dessas sementes. No entanto, as diferenças verificadas na coloração dos frutos e sementes podem ser causadas pela influência das condições ambientais locais ocorridas nas épocas de colheita.

Os frutos da Amburana cearensis, apresentaram pequena variação com relação ao comprimento, largura e espessura, variando em média $68,4 \mathrm{~mm}$ de comprimento, $12,8 \mathrm{~mm}$ de largura e $9,7 \mathrm{~mm}$ de espessura na primeira colheita, para $64,0 \mathrm{~mm}$ de comprimento; $13,9 \mathrm{~mm}$ de largura e $9,6 \mathrm{~mm}$ de espessura na quinta colheita (54 dias após a antese), quando se apresentaram com coloração marrom-escura e ápice enrugado. Na sexta colheita não foi possível a análise de suas dimensões devido à ocorrência da deiscência (Figura 1).

O início da dispersão de sementes de Amburana cearensis (cumaru) ocorre no período mais seco do ano (outubro-dezembro), antes das chuvas, característica da maioria das espécies da caatinga, já que o período das chuvas é relativamente curto (janeiro-maio), portanto, garantindo a sobrevivência da espécie.

Na quarta e quinta colheitas ( 48 e 54 dias após a antese, respectivamente), os frutos apresentaram um decréscimo gradativo em suas dimensões, em consequência da redução do teor de água (Figura 2). Resultado semelhante foi observado por Silva (2002) trabalhando com Cnidoscolus phyllacanthus Pax \& K. Hoffm. No entanto, outros trabalhos resultaram em resultados opostos como o de Alves et al. (2005) trabalhado com Mimosa caesalpiniifolia Benth., Chitarra et al. (2008) com Piptadenia gonoacantha (Mart.) Macbr.; Melo (2001) com Attalea funifera Mart. e Mendes et al. (2005) com Bixa orellana L.

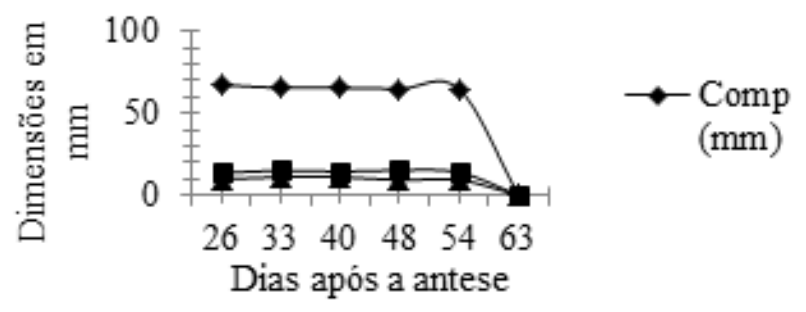

FIGURA 1: Comprimento, largura e espessura dos frutos de Amburana cearensis, em diferentes épocas de colheita após a antese.

FIGURE 1: Length, width and thickness of the fruits of Amburana cearensis, on times different of harvest after anthesis.

Segundo Carvalho e Nakagawa (2000), as sementes aumentam rapidamente em tamanho, atingindo o máximo desenvolvimento em um curto período de tempo, antes mesmo de completar o processo de maturação.

O comprimento, largura e espessura das sementes (Figura 2) apresentaram aumento nas primeiras colheitas $(18,3 \mathrm{~mm}, 9,4 \mathrm{~mm}$ e $6,7 \mathrm{~mm}$, para respectivamente $18,8 \mathrm{~mm}$ comprimento, $11,0 \mathrm{~mm}$ largura e $7,5 \mathrm{~mm}$ em espessura). A partir da quarta colheita (48 dias após a antese) ocorreu um decréscimo gradativo até a sexta colheita (63 dias após a antese) com comprimento de 15,0 mm; largura de $9,6 \mathrm{~mm}$ e espessura de $4,5 \mathrm{~mm}$, essas reduções nas dimensões das sementes coincidem com o decréscimo no teor de água.

Resultados semelhantes foram observados por Martins e Silva (1997), em sementes de Dalbergia nigra (Vell.) Fr.All. ex Benth, onde o teor de água decresceu continuadamente ao longo dos períodos avaliados. $\mathrm{O}$ alto grau de umidade inicial, verificado nas sementes das primeiras colheitas e seu posterior decréscimo, esta relacionado com a importância da água nos processos de enchimento e maturação das sementes. Carvalho e Nakagawa (2000) afirmam que os produtos fotossintéticos nas folhas são depositados na semente em formação, e são utilizados como material de construção e posteriormente como de reserva, sendo necessária a manutenção de elevado grau de umidade, o que ocorre até a massa seca atingir seu valor máximo, quando então se inicia uma rápida desidratação.

De acordo com a Figura 3, verificou-se que o teor de água dos frutos e sementes não diferenciou até os 48 dias após a antese, variando de $75,0 \%$ a $72,2 \%$ para frutos e $77,3 \%$ e $73,7 \%$ para as sementes. 


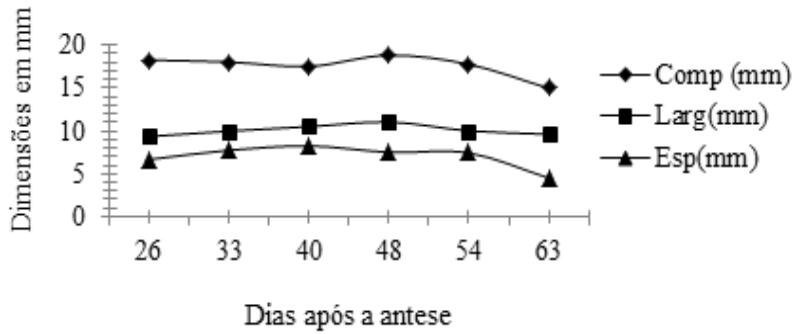

FIGURA 2: Comprimento, largura e espessura das sementes de Amburana cearensis, em diferentes épocas de colheita após a

FIGURE 2: antese.

Length, width and thickness of the seed of Amburana cearensis at different times of harvest after anthesis.

A partir de quinta colheita (54 dias após a antese) houve redução acentuada, os frutos apresentaram $50,0 \%$ e as sementes $49,7 \%$ de água, época esta caracterizada como ponto de maturidade fisiológica das sementes de Amburana cearensis. Quando os frutos apresentaram coloração preta, ápices abertos, início de dispersão de sementes, baixos valores no teor de água dos frutos $(13,6 \%)$ e sementes $(9,5 \%)$, considerou-se que foi alcançado o ponto de colheita. Chitarra et al. (2008), trabalhando com Piptadenia gonoacantha (Mart.) Macbr., observaram que em frutos maduros desta espécie o teor de água foi baixo $(14,2 \%)$, cerca de cinco vezes inferior ao dos frutos verdes $(69,8 \%)$ e cerca de três vezes inferior ao dos frutos com maturação intermediária $(41,7 \%$ frutos marrom-verde) sendo portanto indicado para época de colheita.

Resultados semelhantes quanto ao período ideal para colheita, em que se registraram os maiores porcentuais de germinação, baixo teor de água dos frutos e sementes e coloração dos frutos modificada para uma tonalidade escura e maduros, também foram verificados nos trabalhos apresentados por Alves et al. (2005) em sementes de Mimosa caesalpiniifolia Benth; Martins et al. (2008a) em sementes de jacarandá; Martins e Silva (1997) com Dalbergia nigra (Vell.) Fr. All. ex Benth e Silva (2002) com Cnidosculus phyllacanthus Pax \& K. Hoffm.

Durante o processo de maturação, as sementes de Amburana cearensis sofreram variações na massa seca, nas primeiras colheitas, o acréscimo foi em média de $1,4 \mathrm{~g}$ atingindo o máximo de acúmulo de massa seca na sexta colheita (63 dias após a antese) com 4,5 g, sendo esse acúmulo inverso ao teor de água (Figura 4).

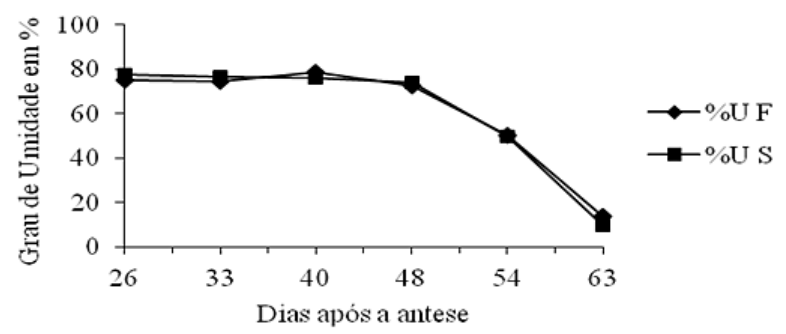

FIGURA 3: Teor de água dos frutos e sementes de Amburana cearensis em diferentes épocas de colheita após a antese. \%UF e \%US: teor de água dos frutos e sementes, respectivamente.

FIGURE 3: Water content of fruits and seeds of Amburana cearensis at different harvest times after anthesis, \% UF e \%US: water content of fruits and seeds, respectively.

$\mathrm{O}$ acúmulo de massa seca em uma semente em formação se faz, inicialmente, de maneira lenta, em seguida começa uma fase de rápido e constante acúmulo, até que um máximo é atingido, o qual é mantido por algum tempo, podendo, no final, sofrer um pequeno decréscimo, como resultado de perdas pela respiração (BARROS, 1986; CARVALHO e NAKAGAWA, 2000).

Essas variações, no processo de maturação, também foram observadas por outros autores como Gemarque et al. (2002), observaram que a massa seca das sementes de Tabebuia impetiginosa (Mart.) Standl., aumentou gradativamente, à medida que os frutos completavam o processo de maturação, atingindo o valor máximo para fruto com $31,0 \mathrm{~g} / 100 \mathrm{~g}$ enquanto para as sementes foram $49,0 \mathrm{~g} / 100 \mathrm{~g}$. Concomitantemente, os teores de água, dos frutos e sementes, decresceram, até atingir valores mínimos de 69,0\% e 51,0\%, respectivamente, por ocasião do início da deiscência e dispersão das sementes. Esse comportamento é típico do processo de maturação das sementes e foi observado também em outras espécies florestais, como a Copaifera langsdorffii Desf. (BARBOSA et al., 1992).

As alterações na massa seca dos frutos e sementes passaram a ser acentuadas a partir da quarta colheita (Figura 4), com aproximadamente 48 dias após a antese. Desse período até o início da dispersão, aos 63 dias após a antese, houve acentuado acúmulo de massa seca.

Essas alterações na massa seca foram resultados que auxiliaram a caracterização do ponto de maturidade 


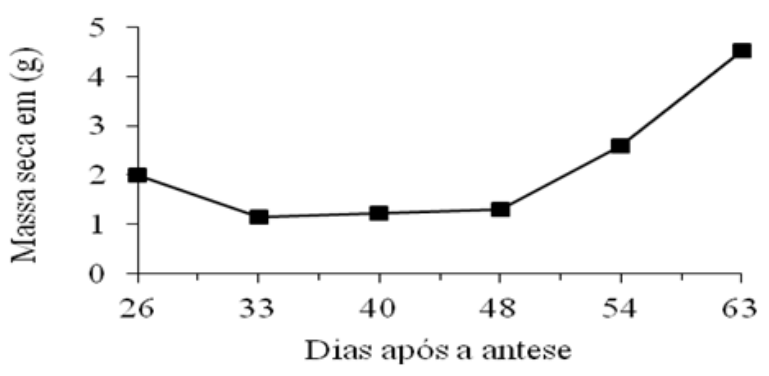

FIGURA 4: Massa seca (gramas) de sementes de Amburana cearensis em diferentes épocas de colheitas após a antese.

FIGURE 4: Dry mass (grams) of seed of Amburana cearensis at different harvest times after anthesis.

das sementes da Amburana cearenses, no entanto, a utilização da massa seca como índice de maturação foi eficaz para determinação do ponto de maturidade fisiológica de sementes de Cedrela fissilis Vell. (CORVELLO et al., 1999); Dalbergia nigra (Vell.) Fr. All. ex Benth. (MARTINS e SILVA, 1997); e Cnidosculus phyllacanthus Pax \& K. Hoffm. (SILVA, 2002). No entanto, Barbosa et al. (1992) observaram que o acúmulo de massa seca nos frutos e nas sementes de Copaifera langsdorffii Desf. não foi um bom indicador de maturidade fisiológica.

Os dados referentes à germinação ajustaramse aos modelos exponenciais (Figura 5), com a máxima percentagem de germinação ocorrendo na sexta colheita (63 dias após antese), neste período as sementes apresentaram 9,5\% de umidade e máximo de massa seca. Comportamento semelhante foi registrado para sementes de Copaifera langsdorffii Desf. (BARBOSAet al., 1992) as quais apresentaram máximos valores de germinação e massa seca e reduzidos valores de teor de água por ocasião da deiscência e dispersão das sementes.

Os resultados obtidos mostram que, nas primeiras colheitas após antese até 48 dias, não foi obtida germinação significante (Figura 6), Germaque et al. (2002) trabalhando com Tabebuia impetiginosa (Mart.) Standl.) e Dranski et al. (2010) com Jatropha curcas L também não obtiveram germinação durante as três primeiras colheitas de sementes, sendo esse resultado justificado pela imaturidade do embrião.

Os dados mostraram que o ponto de colheita de sementes de Amburana cearensis ocorre entre 54 e 63 dias após a antese (quinta e sexta colheitas, respectivamente) época anterior à dispersão, quando as sementes apresentaram teor de água baixo $(9,5 \%)$ e máximo valor de massa seca $(4,5 \mathrm{~g})$. Para Carvalho e Nakagawa (2000), a colheita deve ser realizada quando a semente atingir o ponto de máxima massa seca, pois após este, ocorre rápida desidratação. Aguiar et al. (2007) trabalhando com sementes Caesalpinia echinata Lam, verificaram elevada qualidade fisiológica na pré-dispersão, num intervalo de sete dias antes do ponto de maturidade fisiológica, entre a oitava e a nona semana após a antese, quando os frutos estão na fase de transição de coloração; passando de verde para castanho na época da colheita. No entanto, entre os estádios de colheita testados por Martins et al. (2008), o mais favorável ao processo de germinação foi o dos frutos em início de abertura. Da mesma forma, a maturidade fisiológica das sementes, que é anterior à dispersão de $T$. serratifolia, também foi verificada em sementes de Mimosa caesalpiniifolia Benth. (ALVES et al., 2004) e Tabebuia impetiginosa (GERMAQUE et al., 2002).

$\mathrm{Na}$ determinação da velocidade de germinação (IVG), verificou-se que houve aumento significativo a partir da terceira colheita (40 dias após a antese) até atingir o máximo valor $(2,5)$ na quinta colheita (Figura 6). Considerando a velocidade de germinação, para a obtenção de sementes de alta qualidade fisiológica, o período mais adequado para a colheita é a época de pré-dispersão com aproximadamente 54 dias após antese. Gemarque et al. (2002), trabalhando com Tabebuia impetiginosa, observaram valores crescentes a partir da quarta colheita, culminando com máximos valores na última colheita, coincidindo com o início da dispersão das sementes. Martins e Silva (1997)

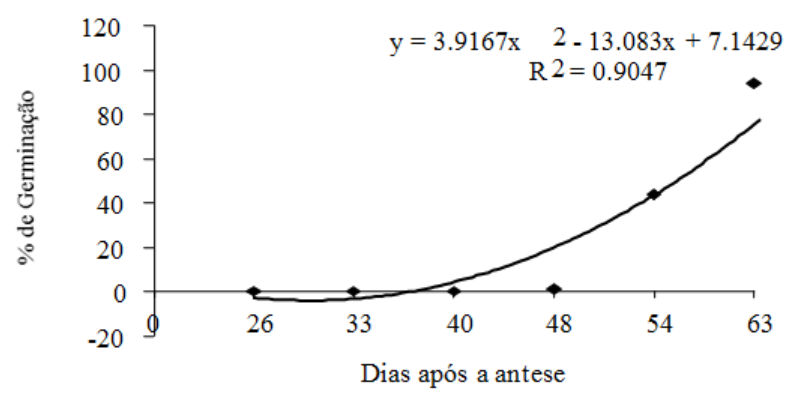

FIGURA 5: Germinação de Amburana cearensis, em diferentes épocas de colheita após a antese.

FIGURE 5: Germination Amburana cearensis, at different harvest times after anthesis. 


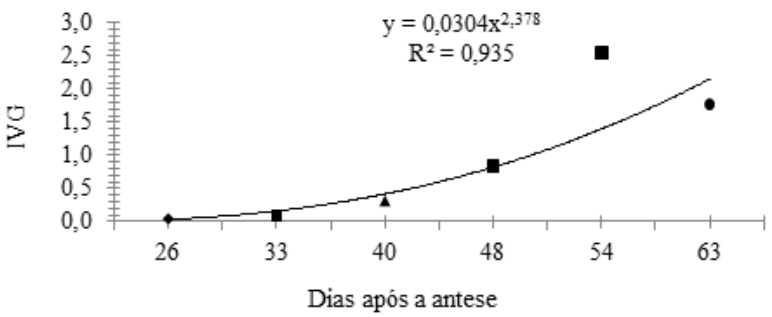

FIGURA 6: Índice de velocidade de germinação (IVG) de Amburana cearensis, em diferentes épocas de colheita após a antese.

FIGURE 6: Germination speed index (IVG) Amburana cearensis, at different harvest times after anthesis.

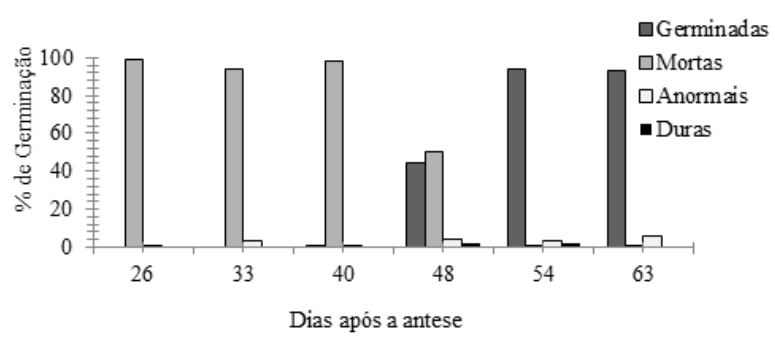

FIGURA 7: Percentagem de sementes germinadas, mortas, duras e plântulas anormais de Amburana cearensis, em diferentes épocas após a antese.

FIGURE 7: Percentage of sprouted seeds, dead, hard and abnormal Amburana cearensis at different times after anthesis.

coletaram frutos de Dalberguia nigra Vell. em diferentes estágios de maturação e verificaram que as sementes procedentes de frutos colhidos no estágio final de maturação foram mais viáveis e vigorosas. No entanto, Firmino et al. (1995) realizaram testes de viabilidade em sementes de Amburana acreana (Ducke), não constataram diferenças significativas entre as percentagens de germinação das sementes dos frutos verdes, pretos e após deiscência, cujos valores encontraram-se entre $76,0 \%$ e $81,0 \%$.

Ao término do teste de germinação foi realizada a análise de sementes não germinadas, e verificou-se que na primeira a terceira colheitas (26 e 40 dias após a antese, respectivamente) a porcentagem de sementes mortas foi em média $97,0 \%$, provavelmente podendo ser atribuído à imaturidade do embrião e ao alto teor de água das sementes. A redução da água e o aumento da massa seca das sementes proporcionaram menor porcentagem de sementes mortas e maiores porcentagens de sementes germinadas $(94,0 \%$ e $93,0 \%$ ), nas quinta e sexta colheitas (54 e 63 dias após a antese, respectivamente), os resultados para as plântulas anormais e sementes duras e mortas não foram relevantes (Figura 7).

\section{CONCLUSÕES}

A colheita dos frutos de Amburana cearensis deve ser realizada aos 54 dias após a antese, quando os frutos apresentam-se fechados com fendas no ápice, de coloração marrom-escura e enrugados, e as sementes apresentam-se com condições fisiológicas favoráveis à germinação e à formação de plântulas morfologicamente normais. Após 63 dias da antese, a colheita das sementes de Amburana cearensis não é recomendada devido à deiscência dos frutos e dispersão natural das sementes, o que ocasiona perda de produção.

\section{REFERÊNCIAS BIBLIOGRÁFICAS}

AGUIAR, F. F. A. et al. Maturação de frutos de Caesalpinia echinata Lam., pau-brasil. Revista Árvore, São Paulo, v.31, n.1, p. 1-6, jan./fev. 2007. AGUIAR, I. B.; PIÑA-RODRIGUES, F. C. M.; FIGLIOLIA, M. B. Sementes Florestais tropicais. Brasília: Associação Brasileira de tecnologia de Sementes, 1993. 350 p.

ALVES, E. U. et al. Dormência e desenvolvimento de sementes de sabiá (Mimosa caesalpiniifolia Benth.). Revista Árvore, São Paulo, v. 28, n. 5, p. 655-662, set./out. 2004.

ALVES, E. U. et al. Maturação fisiológica de sementes de sabiá. Revista Brasileira de Sementes, Londrina, v. 27, n. 1, p. 01-08, 2005.

ASSISTAT Versão 7.5 beta (2008) - Homepage http://www.assistat.com Por Francisco de A. S. e Silva DEAG-CTRN-UFCG.

AVILA, A. L.; ARGENTA, M. S.; MUNIZ, M. F. B. Maturação fisiológica e coleta de sementes de Eugenia uniflora (pitanga), Santa Maria, RS. Ciência Florestal, Santa Maria, v. 19, n. 1, p. 61-68, jan./mar., 2009.

BARBOSA, J. M.; AGUIAR, I. B.; SANTOS, S. R. G. Maturação de sementes de Copaifera langsdorffii Desf. Revista do Instituto Florestal, São Paulo, v. 4, n. único, p. 665-674, 1992.

BARROS,A. S. R. Maturação e colheita de sementes. In: CICERO, S. M.; MARCOS-FILHO, J.; SILVA, 
W.R. Atualização em produção de sementes. Piracicaba: FEALQ/USP, 1986. p.107- 134.

BRASIL. Ministério da Agricultura. Regras para Análise de Sementes. Brasília, Secretária Nacional de Defesa Agropecuária, 1992, 398 p.

CARVALHO, N. M.; NAKAGAWA, J. Sementes: ciência, tecnologia e produção. 4. ed., Jaboticabal, FUNEP, 2000. 588 p.

CHITARRA, J. F. et al. Época de colheita de sementes de pau-jacaré Piptadenia gonoacantha (Mart.) Macbr. Revista Científica Eletrônica de Engenharia Florestal. Graças, v.7, n. 12, p.1-12, ago., 2008.

CORVELLO, W. B. V. et al. Maturação fisiológica de sementes de cedro (Cedrela fissilis Vell.). Revista Brasileira de Sementes, Londrina, v. 21, n. 2, p. 23-27, jul., 1999.

DRANSKI, J. A. L. et al. Physiological maturity of seeds and colorimetry of fruits of Jatropha curcas

L. Revista Brasileira de Sementes, Londrina, v. 32, n. 4, p. 158 - 165, out., 2010.

FIRMINO, J. L.; SANTOS, D. S. B.; SANTOS, B. G. Utilização de alguns testes de viabilidade e vigor e composição química em sementes de cerejeira (Amburana acreana (Ducke) A. C.Smith). Revista Árvore, Viçosa, v. 19, n. 3, p. 286-292, jul./set, 1995.

GERMAQUE, R. C. R.; DAVIDE, A. C.; FARIA, J. M. R. Indicadores de maturidade fisiológica de sementes de Ipê-roxo (Tabebuia impetiginosa (Mart.) Standl.). Cerne, Lavras, v. 8, n. 2, p. 84-91, jul./dez., 2002.

INSTITUO BRASILEIRO DE MEIO AMBIENTE - IBAMA. Lista oficial das espécies da Flora Brasileira ameaçada de extinção. 1992. 52 p.

LOPES, J. C.; SOARES, A. da S. Estudo da Maturação de Sementes de Carvalho Vermelho (Miconia cinnamomifolia (Dc.) Naud.). Ciência Agrotécnica, Lavras, v. 30, n. 4, p. 623-628, jul./ago., 2006.

MAGUIRE, J. B. Speed of germination-aid in selection and evaluation for seedling emergence vigor. Crop Science, Madison, v. 2, n. 1. p. 176-177, jan. 1962.

MARCOS FILHO, J. Fisiologia de sementes de plantas cultivadas. Piracicaba: FEALQ, 2005. $489 \mathrm{p}$.

MARTINS, C. C.; MARTINELLI-SENEME, A.; NAKAGAWA, J. Estágio de colheita e substrato para o teste de germinação de sementes de ipê (Tabebuia chrysotricha (Mart. ex DC.) Standl.). Revista Árvore, Viçosa, v. 32, n. 1, jan./fev. 2008 b.

MARTINS, C. C. et al. Condições climáticas, características do fruto e sistema de colheita na qualidade fisiológica de sementes de jacarandá Revista Árvore, Viçosa, v. 32, n. 4, jul/ago. 2008 a.

MARTINS, S. V.; SILVA, D. D. Maturação e época de colheita de sementes de Dalbergia nigra (Vell.) Fr. All. ex Benth. Revista Brasileira de Sementes, Londrina, v.19, n.1, p.96-99, jan., 1997.

MELO, J. R. V. Maturação, germinação e armazenamento de sementes de piaçaveira (Attalea funifera Mart.). 2001, 115 f. Tese (Doutorado em Agricultura) - Faculdade de Ciências Agronômicas, Universidade Estadual Paulista- SP, 2001.

MENDES, A. M. da S.; FIGUEIREDO, A. F. de; SILVA, J. F. da. Crescimento e maturação dos frutos e sementes de urucum. Revista Brasileira sementes, Pelotas, v.27, n.2, dez. 2005.

SANTOS, A. P. B.; NASCIMENTO, M. F. S.; SANTO, F. S. E. Guia de campo de árvores. Petrolina, v.1, 2009, 64 p.

SILVA, L. M. M. Maturação fisiológica de sementes de Cnidosculus phyllacanthus Pax \& K. Hoffm. In: Morfologia e ecofisiologia de sementes de Cnidosculus phyllacanthus Pax \& K. Hoffm. 2002. $61 \mathrm{f}$. Tese (Doutorado em Agronomia) - Faculdade de Ciências Agrárias e Veterinárias, Universidade Estadual Paulista- SP, 2002. 